Supplement of Atmos. Chem. Phys. Discuss., 15, 30693-30756, 2015

http://www.atmos-chem-phys-discuss.net/15/30693/2015/

doi:10.5194/acpd-15-30693-2015-supplement

(C) Author(s) 2015. CC Attribution 3.0 License.

(c) (i)

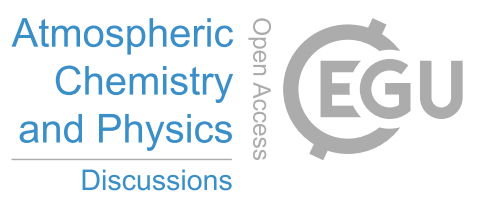

Supplement of

\title{
Atmospheric inversion for cost effective quantification of city $\mathrm{CO}_{2}$ emissions
}

\section{Wu et al.}

Correspondence to: L. Wu (lwu@1sce.ipsl.fr)

The copyright of individual parts of the supplement might differ from the CC-BY 3.0 licence. 
1 The reduced 1-sigma monthly uncertainties for inflated (Figure S1a), original (Figure 8d) and 2 shrunk (Figure S1b) observation errors are (1) 7\%, 6\%, and 5\% respectively for total emission

3 estimates with U network, (2) 16\%, 15\%, and 12\% respectively for building emissions with U 4 network, (3) 19\%, 18\% and 16\% respectively for road emissions with E network, and (4) $520 \%, 18 \%$ and $16 \%$ respectively for energy emissions with $U$ network. Changing the 6 correlation structure in background errors would have an impact of similar order on inversion 7 performance (see Cardinali 2013). We have studied a winter period (January 2011). 8 Compared to winter NEE fluxes, summer NEE fluxes have larger diurnal variations, which 9 may incur larger NEE model errors and larger observation errors. We therefore 10 inflated/shrunk by $100 \%$ the background error standard derivation of the NEE fluxes, and

11 found less than $1 \%$ variations of uncertainty reduction in the total emission estimates by the 12 inversion. For our winter period, the cross correlation between errors in inversion estimate for 13 NEE fluxes and other sectoral fossil fuel CO2 emissions (except building emissions) are 14 nearly zero (Figure 9b-d), which may explain the weak influence of background NEE errors 15 on total fossil fuel $\mathrm{CO} 2$ emission estimates. We also inflated the columns of the observation operator matrix $\mathbf{H}$ that correspond to the NEE fluxes by factors of 3 and 5 respectively to take 17 into account enhanced summer NEE variations. The resulting variations of uncertainty 18 reductions in the total emission estimates were found to be less than $1 \%$. These sensitivity 19 analyses lead us to conclude that our inversions are robust and do not change qualitatively for 20 other months or when tuning the background or observation errors for realistic applications.

\section{Reference}

23 Cardinali, C.: Observation Influence Diagnostic of a Data Assimilation System, in: Data 24 Assimilation for Atmospheric, Oceanic and Hydrologic Applications (Vol. II), edited by: 25 Park, S. K., and Xu, L., Springer Berlin Heidelberg, 89-110, 2013 


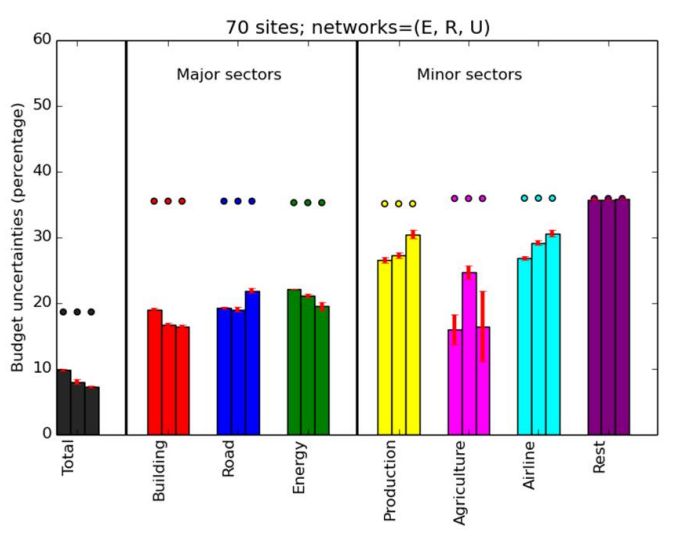

(a)

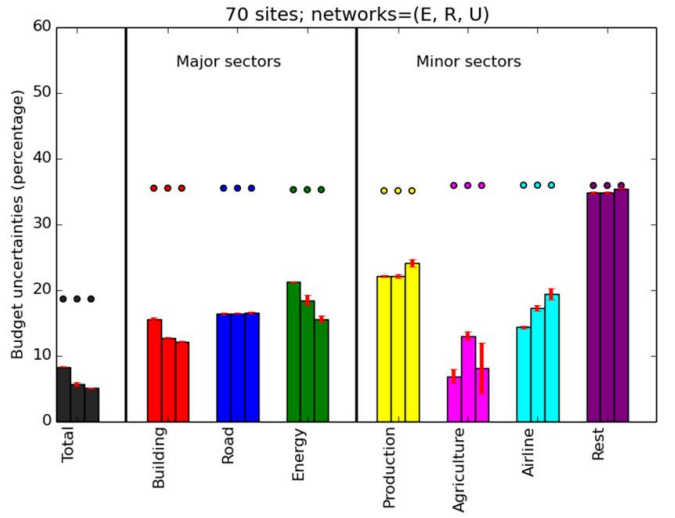

(b)

1 Supplementary Figure S1 (a) Reduction of uncertainties by inversions using three different 2 types of networks of 70 stations with inflated observation error standard derivation (50\% 3 larger). (b) Reduction of uncertainties by inversions using three different types of networks of 470 stations with shrunk observation error standard derivation (50\% smaller). 